\title{
Patterns of food insecurity and participation in food assistance programmes over time in the elderly
}

\author{
Kirang Kim ${ }^{1, *}$ and Edward A Frongillo ${ }^{2}$ \\ 'Department of Preventive Medicine, Hanyang University, College of Medicine, Haengdang-Dong, Sungdong- \\ Gu, Seoul 133-791, South Korea: ${ }^{2}$ Department of Health Promotion, Education, and Behavior, University of \\ South Carolina, Columbia, SC 29208, USA
}

Submitted 4 January 2008: Accepted 5 February 2009: First published online 17 April 2009

\begin{abstract}
Objective: The present study aimed to understand the relationship between need and help-seeking behaviour in older adults by examining the patterns of food insecurity and participation in food assistance programmes (FAP), i.e. the Food Stamp Program and home-delivered meals.

Design: Data from two longitudinal studies were used. The studies were designed to obtain nationally representative information on health, insurance coverage, financial status, family support systems, labour market status and retirement planning, every two years: the Health and Retirement Study (HRS, 1996-2002) and Asset and Health Dynamics Among the Oldest Old (AHEAD, 1995-2002).

Setting: USA.

Subjects: There were 7623 participants for HRS and 3378 for AHEAD.

Results: The older adults appeared to have persistent patterns between food insecurity and participation in FAP, especially in the Food Stamp Program. More persistently food-insecure older adults had higher participation in FAP $(P<0 \cdot 001)$. Food-insecure older adults at one time were more likely to shift from non-participation to participation in FAP the next time than food-secure older adults $(P<0 \cdot 001)$. Regardless of previous food insecurity status, previous participants in FAP were more likely to participate subsequently.

Conclusions: The relationship between need and help-seeking behaviour in older adults was found to follow a persistent positive pattern, determined by looking at the patterns of food insecurity and participation in FAP. Although food insecurity as a need is a good predictor of participation in FAP, it is not enough to fully predict participation in FAP. Help-seeking behaviour (i.e. previous programme participation) is also important in predicting participation in FAP.
\end{abstract}

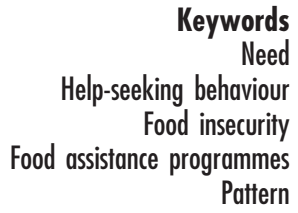

Pattern
Because of decrease in financial reserves and physical strength with ageing, older adults are more likely to face needs making them more vulnerable to delicate health situations and, in turn, leading them to seek help as a compensatory strategy ${ }^{(1-3)}$. If help-seeking behaviour within the context of need were understood, a well-targeted intervention could be created which would reduce the vulnerability of older adults and enhance their quality of life. However, little information is available concerning the relationship between need and help-seeking behaviour among older adults with regard to participation in food assistance programmes (FAP).

Need and help-seeking behaviour are changeable and associated with each other ${ }^{(3,4)}$. The relationship between them can be understood by looking at how the change of one factor influences the change of the other over time. This dynamic relationship can be analysed by examining patterns, because they provide a way of contrasting variation in processes such as stability $v$. change ${ }^{(5)}$. These patterns can serve as a basis for examining factors that predict whether people will follow a stable or variable trajectory. Patterns can also be important in the early stages of exploring many dimensions of long-term processes $^{(6)}$. As a general way for analysing long-term dynamic processes, pattern analysis has been frequently used $^{(7-9)}$. Pattern analyses can provide the following information: (i) whether need and help-seeking behaviour for older adults are constant over time; (ii) whether change in need affects help-seeking behaviour; and (iii) whether more persistently needy individuals seek the most help. The dynamic relationship between need and help-seeking behaviour in older adults can partly be understood by looking at the relationship of food insecurity (i.e. part of need) and programme participation behaviours (i.e. part of help-seeking behaviour). Food insecurity is defined as the limited or uncertain 
availability of nutritionally adequate and safe foods or limited or uncertain ability to acquire acceptable foods in socially acceptable ways ${ }^{(10)}$. Several studies have suggested that food insecurity is an indicator of need for FAP among older adults ${ }^{(1-16)}$. For older adults, who generally require special attention for optimal nutrition, food insecurity has been a risk factor for poor nutritional status, especially in those with physical disabilities ${ }^{(17-20)}$. These older adults have been eligible for federal, state and local food and nutrition assistance programmes ${ }^{(12,14,21-23)}$

Thus, looking at the relationship between food insecurity and programme participation behaviours could help clarify the dynamic relationship between need and help-seeking behaviour in older adults. Therefore, the objectives of the present study were to examine the patterns of food insecurity and participation in FAP over time and to determine their interrelationship as a function of time.

\section{Methods}

\section{Subjects and data source}

The study used two data sets: the Health and Retirement Study (HRS) and Asset and Health Dynamics Among the Oldest Old (AHEAD). HRS and AHEAD are longitudinal surveys designed to obtain nationally representative information on health, insurance coverage, financial status, family support systems, labour market status and retirement planning, collecting data every two years since 1992 and 1993, respectively. The data were collected from faceto-face interviews in a person's home (baseline data), then telephone follow-ups every other year, including proxy interview after death. The response rate ranged from $81 \cdot 7 \%$ to $89.7 \%$ for HRS and from $80.4 \%$ to $92 \cdot 8 \%$ for AHEAD ${ }^{(24)}$.

HRS was administered to people who were between 51 and 61 years old at the time of the first interview and their spouses, whose age was not considered. The initial sample consisted of 12652 persons from a national probability sample of 7607 US households. AHEAD was a companion to HRS and included 7447 non-institutionalized persons aged 70 years or greater and their spouses, whose age was also not considered. Both HRS and AHEAD used a multistage complex sampling strategy with an intentional oversampling of blacks, Hispanics and Florida residents, to increase the representation of eligible black and Hispanic household units and to allow separate state-level analysis of data from Florida respondents.

Because food insecurity was measured since 1995, the present study used data from the four follow-up surveys (i.e. waves) carried out beginning in 1995/1996 (1996, 1998, 2000, 2002 for HRS and 1995, 1998, 2000, 2002 for AHEAD), Thus, the study sample numbered 9481 people who were more than 54 years old for HRS, and 6354 people who were more than 71 years old for AHEAD in 1996 and 1995, respectively. For the analytical sample, only people who were alive during the study period were included. Thus, the total number of study subjects used for the analysis was $7623(80 \cdot 4 \%)$ for HRS and $3378(53 \cdot 2 \%)$ for AHEAD. The average age of the sample was $60 \cdot 8$ (SD $4 \cdot 2$ ) years for HRS and $79 \cdot 6$ (SD 5.8) years for AHEAD. Males accounted for about half of the HRS data set (52.3\%) and $40 \cdot 1 \%$ of the AHEAD data set. The respondents were primarily white for both HRS (81.2\%) and AHEAD $(87 \cdot 4 \%)$. About three-quarters of HRS respondents were living with their spouse (75\%), while only half of AHEAD respondents were living with spouses ( $52 \%$ ).

Study variables were assessed for each of the four years of data collection. Two items based on the US Household Food Security Survey Module (FSSM) ${ }^{(25)}$ were used to measure food insecurity status over the past two years in both HRS and AHEAD: (i) whether the respondents have always had enough money to buy the food they need; and (ii) whether they had skipped meals or eaten less than they felt they should because there was not enough food in the house. A respondent was classified as foodinsecure if he or she reported a negative response to the first question or an affirmative response to the second question. Participation in FAP indicated whether a respondent received the Food Stamp Program (FSP) at any time in the past two years or home-delivered meals (HDM) currently. Both HRS and AHEAD studies are under current Institutional Review Board approval by the relevant committees at the University of Michigan and the National Institute on Aging. Because no personal identifiers were used, the present study was exempted from human subjects review.

\section{Data analysis}

The prevalence of food insecurity and participation in FAP were estimated using sampling weights to adjust for unequal selection probabilities and differences in response rates. HRS and AHEAD include post-stratification weights that calibrate the estimate to the demographic characteristics of the US elderly population ${ }^{(26,27)}$. Weights from each wave were highly correlated, and thus the weight variable for 1998 was used.

The patterns over time were defined by mapping out all possible combinations of events of food insecurity and participation in FAP (sixteen patterns) across the survey waves and then aggregating similar patterns by the number of persistent events (for example, once at any wave or two consecutive times, etc.) to create a smaller number of meaningful patterns. Patterns for individual stability or change in food insecurity and participation in FAP were examined using two successive time points (one interval). Because patterns of the three intervals, 1996 (or 1995) to 1998,1998 to 2000 and 2000 to 2002, were similar in both HRS and AHEAD, these three intervals were combined. Contingency tables were used to estimate the probability for each pattern of relationships between food insecurity and participation in FAP, using the $\chi^{2}$ test for statistical significance. 


\section{Results}

The prevalence of food insecurity and participation in FAP over time are shown in Fig. 1. The prevalence of food insecurity and participation in FSP decreased over time, while the prevalence of participation in HDM increased over time in both HRS and AHEAD.

Table 1 shows the distribution of patterns of food insecurity and participation in FSP and HDM. For HRS and
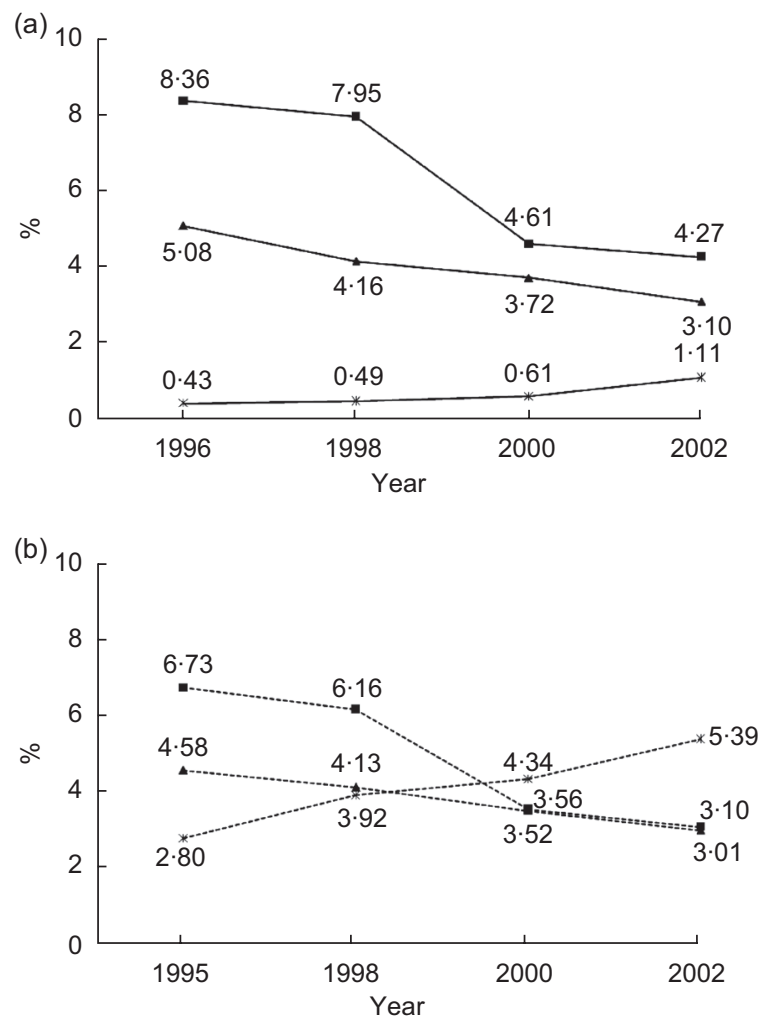

Fig. 1 The prevalence of food insecurity (-口-, - - - - - -) and participation in food assistance programmes (- $\mathbf{\Delta}-,-\cdots-\mathbf{\Delta}-\cdot-$, Food Stamp Program; - *-, ---*---, home-delivered meals) over time: US elderly participating in (a) the Health and Retirement Study (HRS, 1996-2002) and (b) Asset and Health Dynamics Among the Oldest Old (AHEAD, 1995-2002)
AHEAD, $17 \cdot 4 \%$ and $16 \cdot 2 \%$ of older adults, respectively, had ever been food-insecure during those eight years. Among older adults having ever been food-insecure, $41.3 \%$ for HRS and $33.0 \%$ for AHEAD were persistently food-insecure and $10.6 \%$ for HRS and $5 \cdot 5 \%$ for AHEAD were food-insecure at least three consecutive times.

The proportion of people who had ever participated in FSP and HDM was $9.0 \%$ and $2.0 \%$, respectively, for HRS, and $7 \cdot 5 \%$ and $9 \cdot 1 \%$, respectively, for AHEAD. Of participants in FAP, $49.0 \%$ for HRS and $59 \cdot 7 \%$ for AHEAD persistently participated in FSP and $14.7 \%$ for HRS and $31.8 \%$ for AHEAD persistently participated in HDM. FSP participants had more persistent participation than HDM participants (49.0\% for FSP and $14.7 \%$ for HDM in HRS; $59.7 \%$ for FSP and $31.8 \%$ for HDM in AHEAD).

The relationship between individual patterns of food insecurity and participation in FAP over time is shown in Fig. 2. Greater number of times of being food-insecure

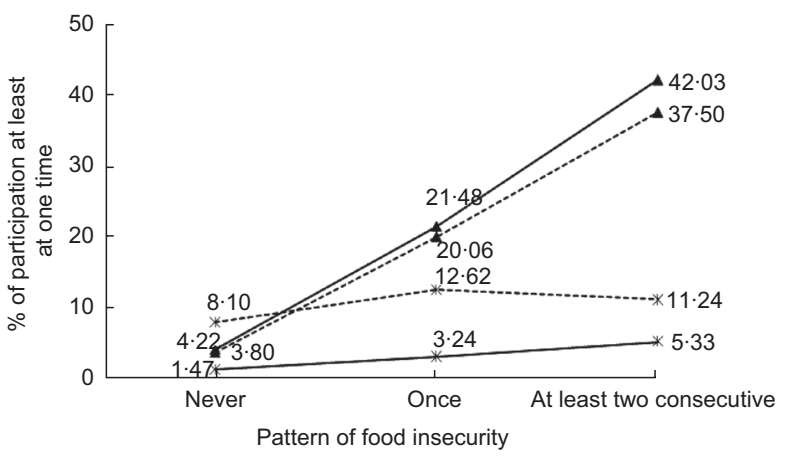

Fig. 2 The percentage of participation in food assistance programmes (FSP, Food Stamp Program; HDM, homedelivered meals) at least one time according the pattern of food insecurity among US elderly participating in the Health and Retirement Study (HRS, 1996-2002) and Asset and Health Dynamics Among the Oldest Old (AHEAD, 1995-2002): $-\boldsymbol{\Delta}-$, FSP in HRS; - $*-$, HDM in HRS; - - - $\mathbf{\Delta}---$, FSP in AHEAD; ---*---, HDM in AHEAD. The percentages of participation were significantly different according to the pattern of food insecurity in each group (FSP in HRS, HDM in HRS, FSP in AHEAD and HDM in AHEAD; $P<0.001)$

Table 1 Distribution of patterns of food insecurity and participation in food assistance programmes: US elderly participating in the Health and Retirement Study (HRS, 1996-2002) and Asset and Health Dynamics Among the Oldest Old (AHEAD, 1995-2002)

\begin{tabular}{|c|c|c|c|c|c|c|}
\hline & \multicolumn{3}{|c|}{ HRS } & \multicolumn{3}{|c|}{ AHEAD } \\
\hline & FIS & FSP & HDM & FIS & FSP & $\mathrm{HDM}$ \\
\hline One or more times & $17 \cdot 4$ & $9 \cdot 0$ & $2 \cdot 0$ & $16 \cdot 2$ & $7 \cdot 5$ & $9 \cdot 1$ \\
\hline Non-persistent & $58 \cdot 7$ & $51 \cdot 0$ & $85 \cdot 3$ & $67 \cdot 0$ & $40 \cdot 3$ & $68 \cdot 2$ \\
\hline Once & $52 \cdot 5$ & $48 \cdot 2$ & $80 \cdot 4$ & $60 \cdot 9$ & $35 \cdot 2$ & $65 \cdot 4$ \\
\hline Intermittent & $6 \cdot 2$ & $2 \cdot 8$ & $4 \cdot 9$ & $6 \cdot 1$ & $5 \cdot 1$ & $2 \cdot 8$ \\
\hline Persistent & $41 \cdot 3$ & $49 \cdot 0$ & $14 \cdot 7$ & $33 \cdot 0$ & $59 \cdot 7$ & $31 \cdot 8$ \\
\hline Two consecutive & $30 \cdot 7$ & $21 \cdot 8$ & $11 \cdot 2$ & $27 \cdot 5$ & $20 \cdot 7$ & $19 \cdot 0$ \\
\hline More than two consecutive & $10 \cdot 6$ & $27 \cdot 2$ & $3 \cdot 5$ & $5 \cdot 5$ & $39 \cdot 0$ & $12 \cdot 8$ \\
\hline Three & $4 \cdot 7$ & $11 \cdot 3$ & $2 \cdot 1$ & $3 \cdot 9$ & $10 \cdot 6$ & $8 \cdot 3$ \\
\hline Four & $5 \cdot 9$ & $15 \cdot 9$ & $1 \cdot 4$ & $1 \cdot 6$ & $28 \cdot 4$ & 4.5 \\
\hline
\end{tabular}

FIS, food insecurity; FSP, Food Stamp Program; HDM, home-delivered meals. 
Table 2 Percentage of people who participated in food assistance programmes at subsequent times $(t)$ according to status of food insecurity and participation at a previous time $(t-1)$ : US elderly participating in the Health and Retirement Study (HRS, 1996-2002) and Asset and Health Dynamics Among the Oldest Old (AHEAD, 1995-2002)

\begin{tabular}{lccccc}
\hline & \multicolumn{2}{c}{$\mathrm{HRS}$} & & \multicolumn{2}{c}{$\mathrm{AHEAD}$} \\
\cline { 2 - 3 } \cline { 6 - 6 } \cline { 5 - 6 } & $\mathrm{FSP}_{t}$ & $\mathrm{HDM}_{t}$ & & $\mathrm{FSP}_{t}$ & $\mathrm{HDM}_{t}$ \\
\hline $\mathrm{FIS}_{t-1}$ & & & & \\
$\quad$ Participation & 61.2 & 43.8 & & 68.8 & 57.5 \\
$\quad$ Non-participation & 7.7 & 1.7 & & 3.2 & 4.9 \\
$\mathrm{FS}_{t-1}$ & & & & \\
$\quad$ Participation & 57.6 & 30.2 & & 64.0 & 49.9 \\
$\quad$ Non-participation & 1.2 & 0.6 & & 0.9 & 3.2 \\
$P$ value & $<0.001$ & $<0.001$ & & $<0.001$ & $<0.001$ \\
\hline
\end{tabular}

FSP, Food Stamp Program; HDM, home-delivered meals; FS, food security; FIS, food insecurity.

was related to greater prevalence of participation at least once in FAP. Participation in FSP increased dramatically with the number of times being food-insecure in both HRS and AHEAD, showing that older adults with at least two consecutive periods of being food-insecure were ten times more likely to participate in the FSP than older adults who had never been food-insecure. Participation in HDM, however, increased slightly. The percentages of participation were significantly different according to the pattern of food insecurity in each group (FSP in HRS, HDM in HRS, FSP in AHEAD and HDM in AHEAD; $P<0 \cdot 001)$.

Table 2 shows the relationship between being food insecure at one time (with either participation or nonparticipation in FAP at that time) and participation in FAP the next time. Of food-insecure older adults at one time who participated in programmes at that time for HRS, $61.2 \%$ and $43.8 \%$ participated the next time in FSP and HDM, respectively. Among food-secure older adults, $57 \cdot 6 \%$ in $\mathrm{FSP}$ and $30.2 \%$ in HDM participated in the programme the next time. For AHEAD, 68.8\% and 57.5\% of food-insecure older adults participated the next time in FSP and HDM, respectively, and $64.0 \%$ and $49 \cdot 9 \%$ of food-secure older adults participated the next time in FSP and HDM, respectively.

Food-insecure older adults at one time were more likely than food-secure older adults to shift from nonparticipation to participation in FAP the next time in both HRS and AHEAD $(P<0 \cdot 001)$. For example, of foodinsecure older adults at one time who did not participate in FSP at that time, $\mathbf{7 \cdot 7 \%}$ participated in the programme the next time. However, of food-secure older adults who did not participate in FSP, $1 \cdot 2 \%$ participated in the programme the next time. Of older adults who did not participate in the programmes the next time among those who were food-insecure and participated at a previous time, 16\% for FSP and 25\% for HDM in HRS and 13\% for FSP and $10 \%$ for HDM in AHEAD were still food-insecure (data not shown).

\section{Discussion}

The present study aimed to understand the relationship between need and help-seeking behaviour in older adults by looking at patterns of food insecurity and participation in FAP (FSP and HDM) over time, and how these patterns were related to each other over time. We found that the older adults appeared to have persistent patterns between food insecurity and participation in FAP, especially in FSP. More consistently food-insecure older adults were more likely to participate continually in FAP. Older adults with one instance of food insecurity were more likely to shift from non-participation to participation in FAP the next time, compared with food-secure older adults. Regardless of previous food insecurity status, previous participants in FAP were more likely to participate again. These findings provide the following information about the relationship between need and help-seeking behaviour: (i) the relationship between need and help-seeking behaviour for older adults is constant over time; (ii) more persistently needy individuals seek the most help; and (iii) changes in need affect help-seeking behaviour.

Participation in FAP over time showed different trends between FSP and HDM. Participation in FSP decreased over time, a finding consistent with that of other studies $^{(23,28)}$, but participation in HDM increased over time. As they become older, more adults become eligible for HDM and require FAP. HDM service is available for older adults in need (i.e. who are food-insecure) because of frailty and physical limitations, as well as economic constraints. In contrast, FSP service is available for adults in need primarily due to economic constraints ${ }^{(18,29)}$. Thus, highly prevalent frailty and physical limitations with increasing age will make older adults more eligible for HDM over time. This change could account for increased HDM participation over time and the higher percentage of HDM participation in AHEAD than in HRS.

Of older adults having participated in FAP, FSP participants were more likely to persistently participate in both HRS and AHEAD as compared with HDM participants. The percentage of FSP participants who participated at least twice consecutively over time was twice or more that of HDM participants ( $49 \% v$. 15\% for HRS and $60 \% v .32 \%$ for AHEAD). The low rate of persistent participation in HDM can be explained by several factors found in previous studies that analysed the factors associated with discontinued participation in HDM. Lack of perception of need, lack of information about the programme, reluctance to accept the services provided, deterioration in the participant's health and no further need for the programme appeared to be prevalent reasons for termination from $\operatorname{HDM}^{(11,30-32)}$.

A higher frequency of food insecurity was strongly related to an increase in participating at least once in FSP, but this relationship was not as strong in HDM. The relatively weak dose-response relationship of food insecurity to participation in HDM most likely resulted 
from food insecurity capturing only part of the concept of need for that programme ${ }^{(1,16,33,34)}$. Lee's findings from programme providers' conceptualization suggested that the need for HDM can be determined by an entire living situation, which might influence an older adult's nutritional and health status, rather than by a single characteristic of their problems such as food insecurity or poverty ${ }^{(16)}$.

The relationship of patterns of food insecurity and participation in FAP across two time points was examined to predict whether older adults changed their behaviour of participation in FAP because of their food insecurity status. The older adults who had a single occurrence of food insecurity were more likely than food-secure older adults to shift from non-participation to participation in both FSP and HDM the next time. Several previous cross-sectional studies have shown similar results. Foodinsecure older adults were more likely to participate in FAP than food-secure individuals ${ }^{(35,36)}$. However, there were non-ignorable numbers of older adults who did not participate in programmes despite being persistently food-insecure in this study (16\% for FSP and 25\% for HDM in HRS and 13\% for FSP and 10\% for HDM in AHEAD), showing consistent findings with other studies ${ }^{(21,37,38)}$. These findings have been explained by a lack of awareness and information about the programmes, the perception that programme benefits are too low to warrant the difficulties, a reluctance to accept food assistance due to stigma, a lack of transportation or physical immobility, among other factors ${ }^{(37,38)}$. This would imply that programmes need to address the issues of accessibility and social stigma. Meanwhile, a few older adults participated in programmes despite being food-secure $(3.7 \%$ for FSP and $3 \cdot 4 \%$ for HDM in HRS and $3 \cdot 1 \%$ for FSP and $0 \cdot 4 \%$ for HDM in AHEAD). The reason could be that they met other eligibility criteria for the programmes such as low income.

The present study showed that, regardless of previous food insecurity status, about two-thirds of previous FSP participants and half of previous HDM participants at one time participated in the programmes the next time. This finding would suggest that previous experience in FAP is another indicator of need for continuance of programme participation. Lee and Frongillo found that food assistance participants had similar or poorer nutritional and health status than non-participants ${ }^{(35)}$. They suggested that participants in FAP may have been the most nutritionally needy, and may have chosen to participate in FAP. The present study showed similar results. When we examined health and economic status, which are indicators of need, according to the status of food insecurity and participation in FAP, food-insecure participants had the worst health status and the lowest economic status, and food-secure participants had the next worse situation (data not shown). Nevertheless, although food insecurity may not fully capture the concept of need for food assistance, food insecurity likely does have the advantage of reflecting the concept of need from the perspective of both the expert and the individual $^{(16)}$, which is a normative need and felt need, in terms of the condition of need by Bradshaw ${ }^{(39)}$.

The present study has several strengths and limitations. It is the first study that has examined the relationship between patterns of food insecurity and participation in FAP over time, and thus contributes to elucidating the relationship between need and help-seeking behaviour in older adults. The longitudinal design with time-intensive event histories permitted us to examine how changes in events are associated dynamically with each other. Because of different characteristics, such as age distribution or participation rate in programmes and different life experiences of the two groups born at different times on average, we analysed the two studies separately. Using different aged populations in the analyses allowed us to test the consistency of our findings. Although the study sample is representative of the elderly US population and consisted of a broad range of older age groups, the respondents in the study were primarily white, which could limit the generalizability of the findings. The analytical sample was a subset of the whole study sample, which could mean that unmeasured factors such as death might have somewhat influenced the results. The measurement of food security using the FSSM might be underestimated because these two items may not be sufficient for accurate assessment of the extent of the food insecurity in older adults ${ }^{(29,40-42)}$, although the FSSM measure has shown validity in discriminating energy intake differences ${ }^{(43)}$. Whether two-year time intervals are optimal to understanding the transition of patterns is not known, which is another limitation in the study.

In conclusion, need and help-seeking behaviours in older adults were studied by looking at patterns between food insecurity and participation in FAP (FSP and HDM), and were found to be variable but the change over time was small, showing a monotonic and positive relationship between them. Although food insecurity as a need was a good predictor of participation in FAP, it could not be enough to fully predict participation in FAP. Help-seeking behaviour (i.e. previous programme participation) was also important in predicting participation in FAP.

\section{Acknowledgements}

Source of funding: There was no funding for this study. Conflict of interest declaration: None of the authors has any conflicts of interest to declare. Authorship responsibilities: K.K. conceived and designed the study with advice from E.A.F., managed and analysed data, and wrote the manuscript. E.A.F. assisted in performing statistical analyses and interpreting the data.

\section{References}

1. Alea N \& Cunningham WR (2003) Compensatory helpseeking in young and older adults: does seeking help, help? Exp Aging Res 29, 437-456. 
2. Espinoza S \& Walston JD (2005) Frailty in older adults: insights and interventions. Cleve Clin J Med $\mathbf{7 2}$, 1105-1112.

3. Nadler A (1983) Social psychology and social issues: research and theory on help-seeking and -receiving in applied Q1 settings. In New Directions in Helping, pp. 3-19 [JD Fisher, A Nadler and BM Depaulo, editors]. New York: Academic Press, Inc.

4. Mojtabai R, Olfson M \& Mechanic D (2002) Perceived need and help-seeking in adults with mood, anxiety, or substance use disorders. Arch Gen Psychiatry 59, 77-84.

5. Courgeau D \& Lelievre E (1992) Reciprocal study of interactions between two events. In Event History Analysis in Demography, pp. 82-98 [D Courgeau and E Lelievre, editors]. Oxford: Clarendon Press.

6. Pavalko EK (1997) Beyond trajectories: multiple concepts for analyzing long-term process. In Studying Aging and Social Change: Conceptual and Methodological Issues, pp. 129-147 [MA Hardy, editor]. Thousand Oaks, CA: SAGE Publications, Inc.

7. Clipp EC, Pavalko EK \& Elder GH (1992) Trajectories of health: in concept and empirical pattern. Behav Health Aging 2, 159-179.

8. Gill TM, Allore HG, Hardy SE \& Guo Z (2006) The dynamic nature of mobility disability in older persons. J Am Geriatr Soc 54, 248-254

9. Kim KR, Kim MK, Shin YJ \& Choi BY (2008) Relationship between the change in overweight status from childhood to adolescence and metabolic syndrome phenotypes: a 9-year retrospective study. Eur J Clin Nutr 62, $748-753$.

10. Anderson SA (1990) Core indicators of nutritional state for difficult-to-sample populations. J Nutr 120, Suppl. 11, 1559-1600.

11. Burt MR (1993) Local and National Comparisons. Final Report of a National Study on the Extent and Nature of Food Insecurity among American Seniors. Washington, DC: Urban Institute.

12. McConnell S \& Ponza M (1999) The Reaching the Working Poor and Poor Elderly Study: What We Learned and Recommendations for Future Research. Washington, DC: Mathematica Policy Research.

13. Nord M (2007) Characteristics of Low-income Households with Very Low Food Security: An Analysis of the USDA GPRA Food Security Indicator. Economic Information Bulletin no. EIB-25. Washington, DC: Economic Research Service, US Department of Agriculture.

14. Ponza M, Ohls JC, Millen BE, McCool AM, Needels KE \& Rosenberg L (1996) The Older American Act Nutrition Programs: National Evaluation of the Elderly Nutrition Program, 1993-1995. Washington, DC: US Department of Health and Human Services.

15. Sharkey JR (2003) Risk and presence of food insufficiency are associated with low nutrient intakes and multimorbidity among homebound older women who receive homedelivered meals. J Nutr 133, 3485-3491.

16. Lee JS (2002) Understanding targeting in the elderly nutrition program: a focus of food insecurity. PhD Thesis, Cornell University.

17. Lee JS \& Frongillo EA Jr (2001) Factors associated with food insecurity among US elderly persons: importance of functional impairments. J Gerontol B Pyschol Sci Soc Sci 56, S94-S99.

18. Lee JS \& Frongillo EA Jr (2001) Nutritional and health consequences are associated with food insecurity among US elderly persons. J Nutr 131, 1503-1509.

19. Sahyoun N \& Basiotis PP (2000) Food Insufficiency and the Nutritional Status of the Elderly Population. Washington, DC: Center for Nutrition Policy and Promotion, US Department of Agriculture.
20. Vailas LI, Nitzke SA, Becker M \& Gast J (1998) Risk indicators for malnutrition are associated inversely with quality of life for participants in meal programs for older adults. J Am Diet Assoc 98, 548-553.

21. Administration on Aging (2004) Fact Sheet: Elderly Nutrition Program. Washington, DC: Administration on Aging, US Department of Health and Human Services.

22. National Council on the Aging (not dated) Older American Act Appropriations - Nutrition Services. Washington, DC: National Council on the Aging.

23. US General Accounting Office (2000) Food Assistance: Options for Improving Nutrition for Older Americans. Report to Congressional Requesters. GAO/RCED-OO-238. Washington, DC: US General Accounting Office.

24. Institute for Social Research, University of Michigan (2002) Survey Design and Performance. http://hrsonlineisrumichedu/ intro/sho_introphp?hfyle=uinfo (accessed June 2008).

25. Bickel G, Nord M, Price C, Hamilton WL \& Cook JT (2002) Measuring Food Security in the United States. Guide to Measuring Household Food Security. Washington, DC: US Department of Agriculture; available at http://www.fns. usda.gov/fsec/FILES/FSGuide.pdf

26. Heeringa SG (1995) Description of the Asset and Health Dynamics (AHEAD) Survey Sample Design. Ann Arbor, MI: Institute for Social Research, University of Michigan.

27. Heeringa SG \& Connor JH (1995) Technical Description of the Health and Retirement Survey Sample Design. Ann Arbor, MI: Institute for Social Research, University of Michigan.

28. US Department of Agriculture (2001) The Decline in Food Stamp Participation: A Report to Congress. Report no. FSP01-WEL. Washington, DC: Food and Nutrition Service, US Department of Agriculture.

29. Wolfe WS, Frongillo EA \& Valois P (2003) Understanding the experience of food insecurity by elders suggests ways to improve its measurement. I Nutr 133, 2762-2769.

30. Choi NG (1999) Determinants of frail elders' lengths of stay in meals on wheels. Gerontologist 39, 397-404.

31. Frongillo EA Jr, Williamson DF, Roe DA \& Scholes JE (1987) Continuance of elderly on home-delivered meals programs. Am J Public Health 77, 1176-1179.

32. Mui AC, Choi NG \& Monk A (1998) Long-term Care and Ethnicity. Westport, CT: Auburn.

33. Blank R \& Ruggles P (1996) When do women use aid to families with dependent children and food stamps? J Hum Resour 31, 57-89.

34. Nadler A (1998) Relationship, esteem, and achievement perspectives on autonomous and dependent help seeking. In Strategic Help Seeking: Implication for Learning and Teaching, pp. 61-94 [SA Karabenick, editor]. Mahwah, NJ: Lawrence Erlbaum Associates.

35. Lee JS \& Frongillo EA Jr (2001) Understanding needs is important for assessing the impact of food assistance program participation on nutritional and health status in US elderly persons. J Nutr 131, 765-773.

36. Millen BE, Ohls JC, Ponza M \& McCool AC (2002) The elderly nutrition program: an effective national framework for preventive nutrition interventions. J Am Diet Assoc 102, 234-240.

37. Food Security Institute (2003) Hunger and Food Insecurity Among the Elderly. Waltham, MA: Center on Hunger and Poverty, Heller Graduate School for Social Policy and Management, Brandeis University.

38. Martin KS, Cook JT, Rogers BL \& Joseph HM (2003) Public versus private food assistance: barriers to participation differ by age and ethnicity. J Nutr Educ Behav 35, 249-254.

39. Bradshaw J (1972) The concept of social need. New Society 19, 640-643. 
40. Quandt SA, Arcury TA, McDonald J, Bell RA \& Vitolins MZ (2001) Meaning and management of food security among rural elders. J Appl Gerontol 20, 356-376.

41. Wolfe WS \& Frongillo EA (1996) Understanding food insecurity in the elderly: a conceptual framework. $J$ Nutr Educ 28, 92-100.
42. Wolfe WS, Olson CM, Kendall A \& Frongillo EA Jr (1998) Hunger and food insecurity in the elderly: its nature and measurement. J Aging Health 10, 327-350.

43. Rose D \& Oliveira V (1997) Nutrient intakes of individuals from food-insufficient households in the United States. Am J Public Health 87, 1956-1961. 